OBITUARY

\title{
Professor C David Marsden 1938-98
}

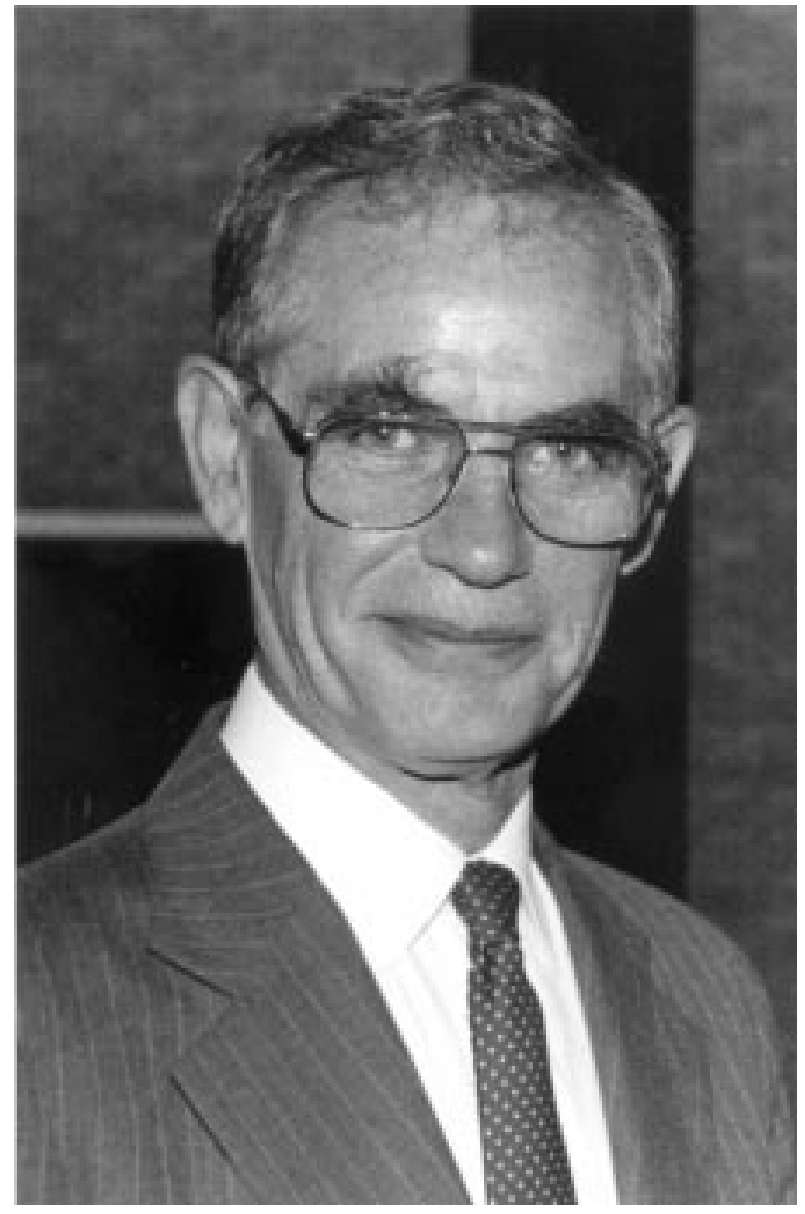

The sad death of Professor David Marsden in September 1998 leaves the world of both movement disorders and clinical neuroscience without one of its most charismatic and outstanding personalities. I first met David when I was a newly appointed Lecturer in Neurology at the Institute of Neurology and he had just arrived as Professor of Neurology. His enthusiasm for teaching and for pushing forward our scientific understanding of the mechanisms of motor control rapidly seduced me, along with many others, into making movement disorders my clinical and scientific specialty. David was subsequently appointed Dean of the Institute of Neurology and ensured that it maintained its individual identity during its incoorporation into University College London.

David had an extraordinary career, becoming Professor of Neurology at the Institute of Psychiatry at the age of only 34 with consultant appointments at both the Maudsley and
King's College Hospitals. He set up research programmes in neurophysiology and neuropharmacology, recruiting John Rothwell and Peter Jenner to drive these areas. John and Peter have subsequently gone on to become acting head of the MRC Human Movement and Balance Unit and Professor of Pharmacology, respectively. David was also instrumental in persuading the UK Parkinson's Disease Society to set up and resource a brain bank which now enjoys an international reputation for its clinicopathological studies and research into the biochemistry of Parkinson's disease. During his time at King's many international fellows visited his unit and have subsequently become opinion leaders in their own right.

One of David's crowning achievements was in bringing order to the chaos that was dystonia. He established that blepharospasm was part of the spectrum and was instrumental in convincing sceptics that dystonia was not a hysterical syndrome. The subsequent discovery of dystonia genes vindicated his approach. He was also one of the first to show that high doses of anticholinergic drugs could be curative in young onset disease. His electrophysiological studies with Pat Merton on long latency reflexes demonstrating their role in maintaining balance were seminal and were duly rewarded when he was elected a Fellow of the Royal Society and awarded a DSc.

David was probably the most prolific clinical neuroscientist ever, being an author on over 800 peer reviewed original reports and writing seminal reviews on the function of the basal ganglia. He was editor of the fournal of Neurology, Neurosurgery, and Psychiatry for 10 years, greatly increasing its citation index during that time and establishing it as a first rank clinical neuroscience journal. With Stan Fahn, he founded the Movement Disorder Society and launched the journal Movement Disorders, which is regarded as the premier specialist journal in its field, and was one of the first to encourage the use of video material with publications.

David's genius was widely recognised and appreciated: he was a visiting professor at 40 institutions and received numerous awards. Despite all this, he remained a very private person and one perhaps got to know him best when sitting down with him for a beer after a busy movement disorder clinic when he would often draw diagrams of basal ganglia function and detail research ideas on any beer mats to hand! David was only too well aware of the descriptive nature of movement disorders (although advances in genetics are now greatly clarifying the situation) and never believed himself infallible. In the future, whenever I am confronted by a particularly complex mixed movement disorder, I will hear his voice in the background gently saying "... and what did we think this patient had the last time that we reviewed him ?"

D J BROOKS 